\title{
Néronde, Saint-Marcel-de-Félines
}

A 89 Balbigny-La-Tour-de-Salvagny

Jean-Marc Lurol

\section{(2) OpenEdition}

\section{Journals}

Édition électronique

URL : http://journals.openedition.org/adlfi/3424

ISSN : 2114-0502

Éditeur

Ministère de la culture

\section{Référence électronique}

Jean-Marc Lurol, « Néronde, Saint-Marcel-de-Félines », ADLFI. Archéologie de la France - Informations [En ligne], Rhône-Alpes, mis en ligne le 01 mars 2009, consulté le 01 mai 2019. URL : http:// journals.openedition.org/adlfi/3424

Ce document a été généré automatiquement le 1 mai 2019.

(C) Ministère de la Culture et de la Communication, CNRS 


\title{
Néronde, Saint-Marcel-de-Félines
}

\author{
A 89 Balbigny-La-Tour-de-Salvagny
}

Jean-Marc Lurol

Identifiant de l'opération archéologique : 10146

Date de l'opération : 2009 (EX)

1 Dans le cadre de la construction de l'autoroute A 89 qui doit à terme relier l'agglomération de Balbigny (Loire) à celle de la Tour-de-Salvagny (Rhône), un diagnostic archéologique complémentaire a été prescrit sur le secteur 11 du projet (Balbigny - St Just-la-Pendue).

2 Ce diagnostic qui concernait les parcelles A 621, A 626 et A 666 (commune de Néronde) et la parcelle B 1142 (commune de St Marcel-de-Félines), constituait une suite à l'évaluation effectuée précédemment sur le secteur 11 au cours des mois de septembre et octobre 2008 (Motte, 2009). Durant cette phase d'évaluation, sept sites avaient été mis en évidence sur l'ensemble du tronçon. C'est donc logiquement que ces nouvelles parcelles ont été retenues pour étude car elles se situent dans un périmètre très proche de certains sites archéologiques repérés : sites de la Ronzière 1, du Rieu, des Dérompés et de Chazelle ).

Les sondages archéologiques ont été menés entre le 23 juin et le 8 juillet 2009. Cent cinquante-sept petites tranchées ont été ouvertes sur l'ensemble des trois zones d'étude. $\mathrm{Au}$ total, $3650 \mathrm{~m}^{2}$ de terrain ont été analysés, ce qui correspond à environ $5,6 \%$ de la surface totale à sonder, estimée à $65000 \mathrm{~m}^{2}$.

4 Les observations réalisées sur ces sondages permettent d'avancer les éléments suivants.

5 Le contexte géologique apparaît assez simple avec des recouvrements supérieurs relativement peu épais (entre 0,40 $\mathrm{m}$ et $1 \mathrm{~m}$ ) entre le socle primaire et le sol actuel. Dans beaucoup de sondages, la présence du substratum (tuf anthracifère du Viséen supérieur) ou de ses altérations apparaissent directement sous la terre végétale. Par endroits sont présents des dépôts de sédiments fins (à matrice limoneuse) qui s'intercalent entre le substrat et la terre végétale et qui correspondent généralement à des colluvions de pente. 
Dans la parcelle B 1142, tous les sondages se sont révélés totalement négatifs, cela malgré l'existence du site médiéval de la Ronzière 1 situé à moins d'une dizaine de mètres.

Sur les autres parcelles A 621, A 626 et A 666, les découvertes se résument à :

- une série de drains relevée dans les sondages 17, 18, 22, 30, 35 et 50 (parcelle A 621), sondages $99,104,114,115,120,124$ (parcelle A 626) et sondages 130,131, 139 et 140 (parcelle A 666). Ces drains ne sont pas tous identiques au niveau de leur mise en oeuvre, certains sont aménagés simplement avec des pierres et des fragments de tuiles, d'autres présentent une construction plus élaborée en forme de caniveau avec des piédroits et des dalles de couverture. L'existence de ces drains est logique dans un contexte géologique relativement étanche. Tous ces éléments ont pour objectif de drainer l'eau qui a tendance à stagner sur des parties hautes des parcelles, où la surface du sol est plane voir en légère cuvette, vers les zones en contrebas. Ces zones en contrebas sont fréquemment occupées par des mares ou des petits étangs.

- un vaste épandage de blocs de granité et de fragments de tuiles relevé dans le sondage 94 (parcelle A 626) et auquel est associé un lot de tessons de céramique datés du haut Moyen Âge (VIle s.- IX $\mathrm{s}$.). Cet ensemble, retrouvé sous la terre végétale entre $0,30 \mathrm{~m}$ et $0,40 \mathrm{~m}$ de profondeur (entre $492 \mathrm{~m}$ et $492,50 \mathrm{~m} \mathrm{NGF}$ ), a été dégagé sur une surface d'environ $120 \mathrm{~m}^{2}$. La fouille partielle (nettoyage) d'une grande partie de ces éléments n'a pas permis de repérer une organisation permettant de caractériser ces vestiges. Parmi tous ces blocs observés, certains présentent des alignements sans que l'on puisse toutefois les interpréter comme des solins. Les blocs de granité, même de grandes dimensions, ne présentent pas de trace de taille. Aucun niveau de sol n'est perceptible et on ne relève pas l'existence d'ensembles fossoyés (fosse, TP) sur toute cette surface.

Tous ces éléments (blocs et tuiles) évoquent les vestiges d'une construction. S'agit-il des restes en place d'un bâtiment qui aurait subi une destruction totale occasionnée par des labours répétitifs? Ou ce sont les éléments déplacés d'un bâtiment proche qui auraient été rejetés dans ce secteur?

11 Aucun vestige de la période VIle ${ }^{\text {S.- }} \mathrm{IX}^{\mathrm{e}} \mathrm{s}$. n'est attesté aux alentours. Le site le plus proche tant sur le plan géographique que chronologique a été retrouvé au lieu-dit "Chazelles " sur la partie haute du terrain (parcelle A 17) localisée à environ $400 \mathrm{~m}$ au nord du sondage 94. Dans ce dernier, l'occupation est toutefois plus récente puisqu'elle est est datée des $\mathrm{X}^{\mathrm{e}} \mathrm{s}$ - $\mathrm{Xll}$ es. Dans le secteur des Dérompés, seules deux parcelles situées hors emprise n'ont pas été sondées. Ces parcelles (A 526 et A 105) se situent à environ $30 \mathrm{~m}$ à l'ouest du sondage 94. Faut-il envisager sur ces espaces un site en rapport avec les découvertes?

Lurol Jean-Marc 
INDEX

Thèmes : drain, fosse

Index géographique : Rhône-Alpes, Loire, Néronde

Index chronologique : IXe siècle apr. J.-C., VIIe siècle apr. J.-C., VIIIe siècle apr. J.-C.

operation expertise (EX)

\section{AUTEUR}

JEAN-MARC LUROL 